\title{
Pedro Calderón de la Barca, La aurora en Copacabana (una comedia sobre el Perú), edición crítica de José Elías Gutiérrez Meza, Madrid / Frankfurt am Main, Iberoamericana / Vervuert, 2018, 338 pp. ISBN: 978-84- 16922-66-6 (Iberoamericana), 978-3-95487-689-1 (Vervuert), 978-3-95487-690-7 (e-Book)
}

\section{A. Robert Lauer}

The University of Oklahoma

ESTADOS UNIDOS

arlauer@ou.edu

[Hipogrifo, (issn: 2328-1308), 8.1, 2020, pp. 657-659]

Recibido: 16-05-2020 / Aceptado: 31-05-2020

DOI: http://dx.doi.org/10.13035/H.2020.08.01.45

La edición crítica de José Elías Gutiérrez Meza de La aurora en Copacabana de Pedro Calderón de la Barca es la segunda y, aparentemente, la más precisa sobre este texto. No hay ningún manuscrito calderoniano sobre este drama. No obstante, existen tres testimonios del siglo XVII: el de Joseph Fernández de Buendía (Madrid, 1672) y el de Bernardo de Hervada (Madrid, 1674), que siguen una lectura a; y el de Juan de Vera Tassis y Villarroel (Madrid, Francisco Sanz, 1688), que sigue una versión $\beta$ (ver el estema de Gutiérrez Meza en la p. 80). Contamos también con tres sueltas $\sin$ fecha, todas derivadas de Vera Tassis, y tres ediciones modernas (aparte de las de conjunto en Apontes, Keil, Hartzenbusch, Valbuena Briones y la Biblioteca Castro [p. 66]): la de Antonio Pagés Larraya (Buenos Aires, Hachette, 1956), la de Saturnino Gallego (La Paz, Bruño, 1992) y la primera edición crítica de Ezra S. Engling (London, Tamesis, 1994). Como demuestra el editor de esta segunda 
edición crítica, Engling siguió el texto de Buendía como base. No obstante, aunque la edición de Hervada de 1674 contiene errores, José Elías Gutiérrez Meza indica, en la crítica de Engling, la omisión del verso 3498, así como lecturas divergentes en los vv. 41, 1223 y 1509. Asimismo, Engling desestima 45 líneas que se mantienen en Hervada y Vera Tassis, las cuales este primer editor crítico transcribe como un apéndice y Gutiérrez Meza, como segundo editor, incorpora al texto base. Finalmente, Everett Hesse, al hacer un cotejo de las dos primeras ediciones de este texto, llega a la conclusión de que la de Hervada es la más cercana al original calderoniano. Otrosí, Gutiérrez Meza propone la viable intervención de Calderón en esta segunda edición (pp. 57-64). Por ende, el editor de la segunda edición crítica usa como texto base la de Hervada, pero subsanándola con lecturas de Fernández de Buendía y Vera Tassis y Villarroel. Se justifica así, pues, esta segunda y más precisa edición crítica de La aurora en Copacabana.

Otro aspecto importante de esta edición es el amplio estudio introductorio de José Elías Gutiérrez Meza. Hay una mayor precisión respecto a la fecha de composición, entre principios de 1664 y 1665, como propone el editor (p. 13). También se plantea una esmerada documentación de representaciones teatrales a partir de la del 16 de septiembre de 1669. La edición ofrece una lista de refundiciones, como la de Pizarro en Copacabana y en sus Indias triunfante España, del poeta llamado Peynado, así como de traducciones al italiano, al alemán y al inglés (pp. 15-16). La edición efectúa una revisión de fuentes históricas, entre ellas la Historia del Santuario de Nuestra Señora de Copacabana (1621) de Alonso Ramos Gavilán, y la Historia general del Perú (1616) del Inca Garcilaso de la Vega, amén de otras. Se descarta, no obstante, la posibilidad del uso de la Descripción del Perú de Reginaldo de Lizárraga por haber permanecido inédita durante el siglo XVII (p. 25). El estudio de Gutiérrez Meza aprecia también el valor histórico no maniqueísta de la obra, así como el aspecto mariano de la misma, el cual parece ser primordial. De infinito valor es el análisis métrico estructural de la obra (p. 41), algo que no se ve necesariamente en todas las ediciones de textos dramáticos, así como el minucioso examen métrico de la misma (pp. 43-47), el cual culmina con un apartado dedicado exclusivamente al uso del canto (pp. 48-51). La bibliografía es amplia y valiosa. Finalmente, las múltiples notas al texto son altamente informativas e inestimables respecto a costumbres prehispánicas y asuntos históricos americanos.

Cada edición es diferente, según los criterios del editor. Algo que se podría haber hecho de otra forma, acaso, sería añadir entre corchetes la información adicional respecto a los personajes del reparto que se encuentra en la edición de Vera Tassis (p. 320), verbigracia, Tucapel [Indio gracioso], Guacolda [Sacerdotisa India], Glauca [India graciosa], etc. Esta adición editorial habría servido para que el lector moderno pudiera haber identificado en forma más precisa, desde el principio, a los varios personajes de la obra. Sin embargo, el editor siguió los testimonios de Buendía y Hervada. Por ende, no estaba obligado a hacerlo. Otrosí, una breve presentación en el estudio de los personajes de la obra, sobre todo los históricos, podría haber sido útil para el lector, quien sabría quién fuera Francisco Pizarro y acaso Diego de Almagro, pero no necesariamente Pedro de Gandía o Lorenzo de Mendoza, conde 
de Coruña. No obstante, el editor da amplia información sobre estos individuos en las notas del texto, así que posiblemente esta adición al estudio habría sido redundante.

Aparte de estas observaciones, que acaso pequen de impertinentes, no tengo ningún reparo respecto a esta importante edición de La aurora en Copacabana; solo admiración por el meticuloso y preciso trabajo editorial de José Elías Gutiérrez Meza, quien en efecto ha dado nueva vida a esta importante obra calderoniana de tema americano/mariano. 